\title{
Perspectivas curriculares das licenciaturas em Ciências Naturais na formação de educadores para Educação de Jovens e Adultos no Ensino Fundamental
}

Curriculum perspectives of the degree course in Natural Sciences in the formation of teacher for Youth and Adult Education in Primary School

Perspectivas curriculares del grado en Ciencias Naturales en la formación de educadores para la Educación de Jóvenes y Adultos en la Escuela Primaria

\author{
Franco de Salles Porto \\ ORCID: https://orcid.org/0000-0002-0931-4968 \\ Universidade de Brasília, Brasil \\ E-mail: franco@unb.br \\ Marcelo Ximenes Aguiar Bizerril \\ ORCID: https://orcid.org/0000-0002-2993-155X \\ Universidade de Brasília, Brasil \\ E-mail: bizerril@unb.br
}

\begin{abstract}
Resumo
O objetivo desse estudo foi analisar como os cursos de licenciatura em Ciências Naturais existentes no Brasil vêm concebendo a modalidade Educação de Jovens e Adultos (EJA) no contexto dos seus Projetos Políticos Pedagógicos (PPPs). Foi realizada uma pesquisa do tipo documental, proveniente dos PPPs referentes a 72 cursos alcançados, e a análise dos dados ocorreu pela abordagem qualitativa, por meio da técnica de análise de conteúdo. O estudo orientouse pelos pressupostos da interdisciplinaridade, fundamentada no materialismo histórico dialético, por entendermos que os licenciandos necessitam de uma formação humana e emancipatória para atuar com os estudantes jovens e adultos, e serem capazes de promover uma educação transformadora das realidades sociais vivenciadas pelos sujeitos trabalhadores. Diante da leitura de cada documento, emergiram três categorias de análise: (1) Interdisciplinaridade como princípios de formação e organização curricular; (2) A EJA como campo de atuação profissional do egresso; (3) Conteúdo das disciplinas que tratam da EJA. Os resultados demonstram que somente 26 cursos (36\%) contemplam a EJA em seus currículos e, destes, apenas nove (12,5\% do total) propõem, nas ementas, ações interdisciplinares para o ensino de Ciências comprometidas com as necessidades sociais da população, proporcionadoras de transformação da realidade. Conclui-se que a maioria das licenciaturas em Ciências não se importam em contemplar a EJA como importante campo de atuação dos egressos, necessitando reorganizar seus currículos afim de reconhecê-la como modalidade de ensino, bem como oferecerem uma formação voltada para a construção de uma sociedade mais justa e igualitária à classe trabalhadora.
\end{abstract}

Palavras-chave: Educação de jovens e adultos; Formação docente; Licenciatura em ciências naturais; Ensino de ciências na EJA.

\begin{abstract}
The objective of this study was to analyze how the degree courses in Natural Sciences existing in Brazil have been conceiving the Youth and Adult Education (EJA) modality in the context of their Pedagogical Political Projects (PPPs). A documentary research was carried out, from PPPs referring to 72 courses reached, and data analysis took place through a qualitative approach, through the content analysis technique. The study was guided by the assumptions of interdisciplinarity, based on dialectical historical materialism, as we understand that undergraduates need human and emancipatory training to work with young and adult students, and be able to promote an education that transforms the social realities experienced by working class. Upon reading each document, three categories of analysis emerged: (1) Interdisciplinarity as principles of training and curriculum organization; (2) EJA as a professional field of activity for the egress; (3) Content of disciplines dealing with EJA. The results show that only 26 courses (36\%) include EJA in their curricula and, of these, only nine (12.5\% of the total) propose, in the syllabuses, interdisciplinary actions for the teaching of Science committed to the social needs of the population, in order to provide a transformation of reality. It is concluded that most science degrees do not mind considering EJA as an important field of activity for graduates, needing to reorganize their curricula in order to recognize it as a teaching modality, as well as offering training aimed at building a fairer and more egalitarian society to the working class.
\end{abstract}

Keywords: Youth and adult education; Teacher training; Degree in natural sciences; Science teaching at EJA. 


\section{Resumen}

El objetivo de este estudio fue analizar cómo las licenciaturas en Ciencias Naturales existentes en Brasil han estado concibiendo la modalidad de Educación de Jóvenes y Adultos (EJA) en el contexto de sus Proyectos Políticos Pedagógicos (PPPs). Se realizó una investigación documental, a partir de las PPPs referidas a los 72 cursos alcanzados, y el análisis de datos se realizó a través de un enfoque cualitativo, a través de la técnica de análisis de contenido. El estudio se guió por los supuestos de la interdisciplinariedad, fundamentados en el materialismo histórico dialéctico, pues entendemos que los estudiantes de pregrado necesitan una formación humana y emancipadora para trabajar con estudiantes jóvenes y adultos, y poder promover una educación que transforme las realidades sociales vividas por los sujetos de trabajo. Al leer cada documento, surgieron tres categorías de análisis: (1) la interdisciplinariedad como principios de formación y organización curricular; (2) EJA como campo profesional para el egresado; (3) Contenido de las disciplinas relacionadas con EJA. Los resultados muestran que solo 26 cursos (36\%) incluyen EJA en sus planes de estudio y, de estos, solo nueve (12,5\% del total) proponen, en los planes de estudio, acciones interdisciplinares para la enseñanza de la ciencia comprometidas con las necesidades sociales. de la población, proveedores de transformación de la realidad. Se concluye que a la mayoría de los grados en ciencias no les importa considerar a la EJA como un campo de actividad importante para los egresados, necesitando reorganizar sus planes de estudio para reconocerla como una modalidad de enseñanza, además de ofrecer una formación orientada a construir una sociedad más justa e igualitaria para la clase trabajadora.

Palabras clave: Educación de jóvenes y adultos; Formación de profesores; Licenciatura en ciencias naturales; Enseñanza de ciencias en EJA.

\section{Introdução}

Apesar da Educação de Jovens e Adultos (EJA) ser constitucionalmente considerada como modalidade de direito da Educação Básica, ainda são grandes os desafios encontrados para se garantir o seu reconhecimento, sobretudo nos cursos de licenciaturas. Arroyo $(2006,2017)$ enfatiza que, por tempos, este segmento de ensino nunca foi prioridade no âmbito das reformas políticas curriculares de formação docente.

Atrelados ao amparo legal, diversos estudos que tratam do tema constatam a EJA como objeto de conhecimento secundarizado, para não dizer esquecido, em grande parte dos programas de curso das licenciaturas do país. Por consequência, apontam que a preparação dos futuros professores para atuarem nesta modalidade localiza-se aquém do esperado, não assegurando o direito por educação com qualidade para todos os sujeitos que dela participam (Ventura, Bomfim, 2015; Soares, Pedroso, 2016; Craveiro, Freitas, 2017; Sant'ana, Mello \& Stramare, 2017; Cruz, 2018; Rêses, Castro \& Barbosa, 2018).

Nesse sentido, compreendemos com Gadotti e Romão (2011) ser imperativo a todo educador se apropriar dos contextos socioculturais e desejos diversificados e heterógenos dos sujeitos da EJA, que são diferentes da criança, cuja experiência de vida está apenas começando.

Por a EJA ser composta, em sua maior parte, de indivíduos pobres, negros, moradores das periferias urbanas, dos campos, indígenas, quilombolas, oprimidos, destituídos e privados de condições básicas para subsistência, se faz necessário uma educação que possa contribuir na transformação de suas realidades sociais e econômicas, em muitos casos, desumanas.

Considerar a realidade diversa e os desafios da EJA implica em um currículo formativo de natureza emancipadora, em que o educador precisa estar ciente das causas e dos problemas sociais, econômicos e políticos que enfrentam o público da EJA, para assim reconhecer seu papel como agente interventor de transformação social desta realidade. Educadores e educandos da EJA necessitam conhecer esse paradigma político do Estado opressor, que os inferiorizam e desumanizam. Esta é uma forma de tomarem consciência de suas origens para entender-se e, consequentemente, transformar-se (FREIRE, 2009).

Perante o exposto, a presente pesquisa trouxe esta discussão para o campo das propostas curriculares dos cursos de licenciatura em Ciências Naturais/da Natureza, que visam formar professores de Ciências para os anos finais do Ensino Fundamental e sua interface com a EJA. Como Delizoicov, Angotti e Pernambuco (2007), entendemos que neste território conflituoso de disputas hegemônicas, pautadas em valores de tendências mercantilistas, os professores de Ciências exercem papel imprescindível e insubstituível para o processo de luta por uma sociedade igualitária, principalmente com estudantes das classes economicamente mais desfavoráveis. 
Sintetizados na ótica do materialismo histórico dialético, de pensamento marxista, sob o qual se embasa o presente estudo, partimos do pensamento de que a formação de professores, e em particular os de Ciências para atuarem com a educação popular, especialmente com a EJA, deva constituir-se a partir de um currículo estruturado em torno de uma perspectiva de formação interdisciplinar crítica e radical.

Com base nesse referencial, compreende-se que a interdisciplinaridade deva ser tomada como conceito fundado no contexto da práxis transformadora, a qual propõe transcender o plano fenomênico das disciplinas curriculares, permitindo romper com a tradicional lógica disciplinar de caráter fragmentário do saber, imposta por políticas educacionais capitalistas. Determinações estas que impedem um olhar mais amplo e crítico dos educadores em formação sobre uma determinada realidade em sua totalidade concreta (Frigoto, 2008).

A prática interdisciplinar, concatenada à filosofia da práxis, segundo Mueller, Bianchetti e Jantsch (2008), Feitosa (2019) e Ramos e Ferreira (2020), considera que teoria e prática (consciência e ato) precisam estar relacionadas, em que uma (re)orienta a outra para compreensão de certo conhecimento em sua totalidade, que se dá a partir da análise dialética entre as partes (disciplinas) que compõem esse todo.

Assim, o presente estudo buscou responder a seguinte questão: a maneira pela qual a interdisciplinaridade é compreendida nos currículos das licenciaturas em Ciências como proposta de formação, quando materializada nas ementas que circundam as disciplinas dedicadas à temática da EJA, está organizada de modo a permitir aos licenciandos uma visão crítica de mundo em sua totalidade com potencial transformador, capaz de educar jovens e adultos para tecerem sua própria emancipação?

Logo, o objetivo geral consistiu em compreender como os cursos de Licenciatura em Ciências Naturais, existentes no Brasil, concebem o ensino interdisciplinar e como veem contemplando a Educação de Jovens e Adultos.

Como objetivos específicos, pretendeu-se localizar e descrever as Licenciaturas em Ciências Naturais que se encontram em vigor no país, e em cada curso: (i) evidenciar e discutir a ocorrência da concepção de interdisciplinaridade como processo formativo; (ii) identificar o grau de importância dada a modalidade EJA como campo de atuação do egresso; (iii) analisar os conteúdos das ementas dos componentes curriculares que abordam a EJA.

Para alcançar a questão e os objetivos apresentados, a pesquisa teve como fonte de dados os Projetos Políticos Pedagógicos (PPPs) dos cursos e o contexto das ementas dos componentes curriculares direcionados à EJA. Portanto, o trabalho refere-se a um estudo de análise documental, realizada a partir da técnica de análise de conteúdo com abordagem qualitativa dos dados. Destaca-se que para a construção e reformulação destes documentos, deve-se considerar as exigências curriculares da legislação vigente do Ministério da Educação (MEC) dirigidas aos cursos superiores.

Contudo, cabe lembrar que a interpretação das Diretrizes e a execução dos projetos fica sob a incumbência de cada Instituição de Ensino Superior (IES), por isso o motivo do nosso interesse em saber "o quê" e o "como" está sendo proposto aos licenciados do curso de Ciências no tocante à EJA.

Goddson (1995) entende que o currículo escrito nos proporciona "um testemunho, uma fonte documental, um mapa do terreno sujeito a modificações, constitui também um dos melhores roteiros oficiais para a estrutura institucionalizada da escolarização" (p. 21). O autor sublinha que o currículo, apesar de ser um instrumento de controle e de reprodução das relações sociais de dominação vigente, é uma fonte documental rica de informações em que, por meio da sua estrutura como construção social, pode desvelar o modelo verdadeiro de educação que se almeja.

É importante enfatizar que estudos desta natureza, que tratam especificamente da EJA nos currículos dos cursos de Ciências Naturais/Natureza, destinados à formação de professores para atuarem nos anos finais do Ensino Fundamental, ainda não foram realizados. Assim sendo, a proposta por si só justifica o estudo, dada a relevância do tema. 
Fundamentado na pesquisa documental, esta investigação apoiou-se em referenciais inspirados na concepção filosófica do materialismo histórico dialético e da teoria de tendência progressista crítico social dos conteúdos curriculares, como Gaudêncio Frigotto (2008); Ivo Tonet (2013); Juarez Thiesen (2014); Mariana Cassab (2016); Miguel Arroyo (2006, 2017) e Raphael Feitosa (2019), dentre outros autores influenciados pelas obras de Paulo Freire.

Diante disso, a pesquisa se encontra estruturada em três etapas. Na primeira, situamos o panorama atual das instituições formadoras de professores de Ciências no país e os aspectos metodológicos da pesquisa. No segundo momento, apresentamos e discutimos os dados da pesquisa, analisando a concepção do termo interdisciplinaridade, a EJA como campo de atuação dos licenciandos e os conteúdos previstos nas ementas das disciplinas que tratam do tema, constantes em cada currículo de cada curso pesquisado. Por fim, as considerações depreendidas da pesquisa.

\section{Metodologia}

\subsection{Levantamento do panorama atual das Licenciaturas em Ciências Naturais/da Natureza}

Mediante levantamento no portal eletrônico e-MEC ${ }^{1}$, iniciado em agosto de 2020 e atualizado até julho de 2021, identificamos que até o ano de 2006 havia apenas nove IES públicas que se propunham a formar professores em Ciências Naturais (Universidade Estadual do Pará; Universidade Federal (UF) do Amazonas, UF Bahia, UF Pará, UF Roraima, UF São Paulo-USP, Universidade de Brasília, UF Mato Grosso e o Instituto Federal Fluminense).

Em consequência da abertura dada pelo Governo Federal à expansão do Ensino Público Superior, a partir de 2007 houve um crescimento significativo no número de IES que criaram o curso de Licenciatura em Ciências Naturais (LCN), de modo que no ano de 2016, dez anos depois, o país contava com 54 instituições que desenvolviam tal curso, representados por três modalidades de Educação: Ensino Presencial (EP), Alternância (LEdoC ${ }^{2}$ ) e Educação à Distância (EAD).

Durante esses anos, algumas das instituições também expandiram a oferta do curso para mais de um turno ou campus, em diferentes municípios. Deste modo, por meio dos dados, contabilizamos 45 instituições públicas que habilitam professores de Ciências para atuarem nos anos finais do Ensino Fundamental, não tendo sido localizadas instituições privadas. Juntas, ofertam 87 cursos de Licenciatura em Ciências Naturais/Natureza no Brasil, ativamente presentes em todas as regiões brasileiras.

De acordo com a Tabela 1, das 45 instituições a maioria está localizada na região Sudeste, doze (26,7\%), seguida do Nordeste, onze (24,4\%). Porém, a região Norte, com número menor de instituições, oito (17,8\%), centraliza a maior parte dos cursos disponíveis no país, com 25 (28,7\%). Da mesma forma, a região Sul, com menor quantidade de instituições, disponibiliza três cursos a mais que o Sudeste, $15(17,2)$. Isto se deve ao fato de a região Sudeste ser a única em que cada instituição dispõe de apenas um único curso de LCN.

\footnotetext{
${ }^{1} \mathrm{O}$ sistema e-MEC, em funcionamento desde janeiro de 2007, permite consultar as Instituições de Ensino Superior brasileiras quanto ao cadastramento e a situação atual dos seus cursos de graduação.

${ }^{2}$ As licenciaturas em educação do campo (LEdoC) atuam em regime de alternância entre Tempo Universidade e Tempo Comunidade.
} 
Tabela 1 - Número de Licenciaturas em Ciências Naturais ofertadas por instituições públicas, conforme regiões e modalidades.

\begin{tabular}{|c|c|c|c|c|c|c|c|c|c|c|}
\hline \multirow{3}{*}{ Região } & \multirow{2}{*}{\multicolumn{2}{|c|}{$\begin{array}{l}\text { Número de } \\
\text { Instituições }\end{array}$}} & \multicolumn{6}{|c|}{ Número de cursos ofertados por modalidade } & \multirow{2}{*}{\multicolumn{2}{|c|}{$\begin{array}{l}\text { Geral de Cursos } \\
\text { disponibilizados }\end{array}$}} \\
\hline & & & \multicolumn{2}{|c|}{ Presencial } & \multicolumn{2}{|c|}{$\begin{array}{c}\text { Educação do } \\
\text { Campo }\end{array}$} & \multicolumn{2}{|c|}{ EAD } & & \\
\hline & $\mathbf{N}^{\mathbf{0}}$ & $\%$ & $\mathbf{N}^{\circ}$ & $\%$ & $\mathbf{N}^{\mathbf{0}}$ & $\%$ & $\mathbf{N}^{\mathbf{o}}$ & $\%$ & $\mathbf{N}^{\circ}$ & $\%$ \\
\hline Centro-Oeste & 6 & 13,3 & 6 & 12,3 & 4 & 13,3 & 1 & 12,5 & 11 & 12,6 \\
\hline Nordeste & 11 & 24,4 & 13 & 26,5 & 7 & 23,3 & 4 & 50,0 & 24 & 27,6 \\
\hline Norte & 8 & 17,8 & 18 & 36,7 & 6 & 20,0 & 1 & 12,5 & 25 & 28,7 \\
\hline Sudeste & 12 & 26,7 & 7 & 14,3 & 5 & 16,7 & 0 & 0,0 & 12 & 13,9 \\
\hline Sul & 8 & 17,8 & 5 & 10,2 & 8 & 26,7 & 2 & 25,0 & 15 & 17,2 \\
\hline Total & 45 & 100,0 & 49 & 100,0 & 30 & 100,0 & 8 & 100,0 & 87 & 100,0 \\
\hline
\end{tabular}

Fonte: Elaborado pelos autores a partir de dados levantados pelo sistema e-MEC.

Quanto às modalidades, a LCN é mais frequentemente ofertada no modo presencial, nas regiões Norte e Nordeste, com 18 e 13 cursos, respectivamente. A Licenciatura do Campo aparece como a segunda modalidade que mais oferta o curso, concentrados nas regiões Sul e Nordeste, com oito e sete cursos, respectivamente. Importante enfatizar que identificamos 45 cursos LEdoC, porém apenas 30 com habilitação em Ciências Naturais. Já dos cursos disponibilizados em EAD, metade está na região Nordeste, com 4 cursos. O Sudeste é a única região que não foi contemplada por esta modalidade.

Em concordância com suas modalidades, os cursos de LCN são ofertados por 37 Universidades Federais, duas Estaduais e seis Institutos Federais, distribuídos em quase todos os estados brasileiros, com exceção de Tocantins, Alagoas e Sergipe.

Estas licenciaturas reconhecem o curso sob várias denominações, como Licenciatura em: Ciências Naturais; Ciências da Natureza; Ciências da Vida e da Terra, e Interdisciplinar em Ciências da Natureza. Para este trabalho optamos em usar o termo Licenciatura em Ciências Naturais quando nos referirmos a esses cursos, em razão de ser o nome mais utilizado pelas instituições conforme evidenciado no sistema e-MEC.

\subsection{Percurso metodológico}

Para a concretização desta pesquisa foi adotada a abordagem qualitativa, que trata de uma investigação documental do tipo analítica e descritiva, envolvendo dados já existentes.

A pesquisa documental, conforme Lüdke e André (1986), consiste num intenso e amplo exame de documentos que ainda não sofreram nenhum trabalho de análise, ou que podem ser reexaminados, buscando-se outras interpretações ou informações complementares. Entende-se como documentos, os materiais escritos que possam ser utilizados como fonte de informação, como leis e regulamentos, normas, pareceres, livros, estatísticas e arquivos escolares (Guba; Lincoln, 1981).

Para tanto, o estudo tomou como base de informações documentais os Projetos Políticos Pedagógicos (PPPs) produzidos pelas IES, que ofertam cursos de licenciatura em Ciências Naturais/Natureza no país.

Inicialmente, pretendeu-se analisar todos os PPPs elaborados pelas 45 IES, que juntas ofertam 87 cursos conforme descrito anteriormente. Porém, após acessarmos o endereço eletrônico de cada uma dessas IES para obtenção dos documentos, verificamos que 15 Instituições não disponibilizaram, em seus portais eletrônicos, no período da pesquisa, alguns dos currículos pertinentes ao curso em evidência, considerados como documentos de domínio público e sem restrições a qualquer tipo de usuário. 
Por consequência, contatamos com os coordenadores destes cursos via e-mail, solicitando o envio dos respectivos projetos de curso. Em resposta obtivemos o retorno de seis instituições, que nos encaminharam os documentos requeridos. Provavelmente um dos motivos de não termos sidos atendidos por todas as coordenações se deve ao isolamento social sofrido no ano, em virtude da pandemia da Covid- $19^{3}$.

Em razão do fato, a pesquisa não teve acesso ao PPP de 15 cursos (17\%). Destes, sete de modo Presencial (quatro localizados no estado do Pará, um em Roraima, um na Bahia e outro no Ceará); seis em Licenciatura do Campo (dois no estado do Pará, um em Minas Gerais e três no Piauí) e dois na modalidade EAD (um no estado do Piauí e outro em Pernambuco).

Assim sendo, o estudo contou com os PPPs de 72 (83\%) cursos de LCN existente no país para análise (42 Presenciais, 24 Educação do Campo e 6 em EAD), obtidos por intermédio de 40 IES públicas (34 Universidades Federais, 2 Universidades Estaduais e 4 Institutos Federais).

De posse de cada um dos currículos disponibilizados para investigação, os dados de interesse da pesquisa foram primeiramente levantados por meio de leitura integral de cada documento. Durante a leitura, percebeu-se que alguns dos cursos proporcionam aos estudantes habilitações para outra(s) licenciatura(s), com objetivo de estenderem suas atividades docentes também ao Ensino Médio, nos campos de conhecimento da Física, Biologia, Química e Matemática.

Devido as habilitações diversificadas, apresentadas por determinados cursos, atentamos que este estudo demarcou os aspectos correspondentes a formação dos estudantes que receberão, exclusivamente, o diploma de Licenciatura Plena em Ciências Naturais, para atuarem nos anos finais do Ensino Fundamental. Portanto, componentes curriculares direcionados à EJA para o Ensino Médio não foram analisadas.

Assim, conforme lia-se cada um dos PPPs, estes eram registrados em um formulário de análise, identificados sequencialmente por ordem numérica de 1 a 72, seguidos do nome, estado, regionalização da instituição, modalidade (Presencial, do Campo ou EAD), ano de implementação do curso e de elaboração de cada projeto. Posteriormente, foi incorporada à tabela todos os excertos selecionados com as informações obtidas, consideradas necessárias aos objetivos da pesquisa.

Em seguida houve nova leitura dos dados apontados nos formulários, a fim de reconhecermos os indicadores mais recorrentes para definição de categorias para posterior análise dos conteúdos, seguindo a proposta de Bardin (2010). Conforme a autora, o método de análise de conteúdo compreende as fases de leitura geral do material coletado; codificação para formulação de categorias de análise; recorte do material, em unidades; inferência e a interpretação.

Com tal processo, emergiram três categorias de análise, surgidas em momentos distintos e específicos da leitura, nos quais foram considerados o que cada uma delas continha em comum nos currículos investigados. Estas categorias são: (1) Princípios orientadores de formação e organização curricular - refere-se ao tema da interdisciplinaridade; (2) Campo de atuação profissional do egresso - relativo à modalidade Educação de Jovens e Adultos; (3) Componentes curriculares, concernentes às disciplinas que tratam da EJA.

Salientamos que as finalidades de cada uma dessas categorias serão discutidas no decorrer de suas análises, nas subseções que se seguem.

A fim de resguardarmos a identidade dos cursos, os excertos textuais citados nas análises foram identificados por meio do número correspondente à sequência em que se deu a leitura de cada proposta de curso, de 1 a 72, seguido da região e modalidade (EP - Educação Presencial; EC - Educação do Campo; EAD - Educação a Distância), como, por exemplo: 2-NorteEAD; 10-Sudeste-EP e 53-Centro-Oeste-EC.

\footnotetext{
${ }^{3}$ A COVID-19 é uma doença infecciosa, causada pelo novo coronavírus (SARS-CoV-2), que se espalhou pelo mundo, caracterizada pela Organização mundial de Saúde como uma pandemia, a qual se refere à distribuição geográfica de uma doença, levando inúmeros países a determinarem períodos de isolamento social. No Brasil a pandemia teve início em 26 de fevereiro de 2020.
} 


\section{Análise dos Dados e Discussão dos Resultados}

Para adentrarmos na análise dos resultados consideramos ser indispensável mencionar, primeiramente, o ano em que cada PPP investigado foi aprovado. Considerar a data em que foram implementados permite depreender e elucidar as políticas educacionais utilizadas como base norteadora, dado o contexto da época em que foram produzidos, viabilizando maior propriedade na interpretação dos dados.

Desta forma, identificamos que os 52 PPPs que contemplam o conjunto de 72 cursos de LCN analisados, foram assentidos em períodos diferenciados, delimitados entre 2008 e 2019 como demonstrado no Gráfico 1.

Gráfico 1 - Ano de aprovação dos PPPs vigentes relativos aos cursos de LCN analisados.

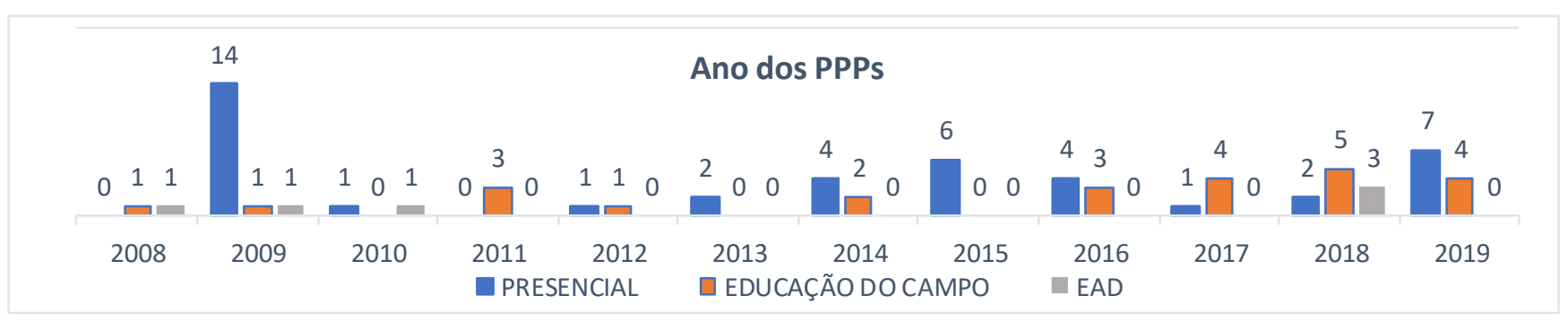

Fonte: Elaborado pelos autores, a partir de dados levantados em cada Projeto de Curso.

Com base nos dados do Gráfico 1 e da leitura de cada PPP, referente aos marcos legais que subsidiaram suas formulações, evidenciamos a existências de 39 cursos com currículos concebidos entre os anos de 2008 e 2015 , cujas elaborações se deram em consonância com as Resoluções CNE/CP $n^{\circ} 01$ e $n^{\circ} 02$ de 2002, as quais instituíram as primeiras Diretrizes Curriculares Nacionais (DCN) para os Cursos de Licenciatura.

Quanto aos demais cursos, 33, com PPPs aprovados entre os anos de 2016 e 2019, foram formulados em concordância com a Resolução CNE/CP n 02 de 2015, que definiram as DCNs para a formação inicial em nível superior (cursos de licenciatura, cursos de formação pedagógica para graduados e cursos de segunda licenciatura) e para a formação continuada.

Posto isso, depreendemos que nenhum PPP fora (re)elaborado no âmbito da mais recente Resolução, a CNE/CP N 2, publicada em 2019, que instituiu as DCNs para a Formação Inicial de Professores para a Educação Básica e estabelece a Base Nacional Comum para a Formação Inicial de Professores da Educação Básica - BNC (BRASIL, 2019).

Diante dessa constatação, observa-se que dos 72 cursos em análise todos estão em período de transição, devendo adequar seus projetos de curso às novas DCNs, aprovadas em 2019. Igualmente, deve-se levar em conta que mais da metade dos cursos, 39 (54\%), sequer atualizaram seus PPPs junto às Diretrizes de 2015.

\subsection{Categoria interdisciplinaridade como princípio orientador de formação e de organização curricular}

Esta categoria, citada no enunciado, surgiu ao direcionarmos nossos olhares diante das redações produzidas por cada PPP, a fim de localizarmos, a priori, a expressão interdisciplinaridade. Nosso interesse foi buscar compreender qual o sentido do termo adotado por esses documentos como proposta de formação e de organização curricular.

Para esse fim, atentamo-nos especialmente ao âmbito de suas premissas, no tocante à fundamentação teórica aceita para embasamento conceitual da interdisciplinaridade, bem como as bases norteadoras adotadas para construção e organização pedagógica da prática interdisciplinar entre as disciplinas/componentes.

Ressaltamos que nesta categoria não foram analisadas as ementas das disciplinas que integram as matrizes de cada curso, pois os componentes curriculares que se constituíram como nosso objeto de interesse são os que se referem exclusivamente à formação para a modalidade EJA, os quais serão discutidos posteriormente. 
De maneira geral, os currículos fazem referência ao termo interdisciplinaridade como forma de superação dos problemas históricos de disciplinas isoladas e fragmentadas. E, de modo específico, percebeu-se a interdisciplinaridade interpretada de forma diferenciada, com aproximações conceituais que apontam para configurações sob três perspectivas, a saber: modismo; racionalidade técnico-prática (tecnicista pragmático) e emancipatória (práxis educativa).

Entendemos como modismo, os cursos que assumem o termo interdisciplinaridade simplesmente para satisfazer algo que ganhou notoriedade nos meios educacionais ao longo dos anos. Como racionalismo técnico pragmático, denominamos os currículos que assumem a formação interdisciplinar associada a um método de trabalho didático-pedagógico tratado de forma instrumental, focado num ensino de natureza prático utilitário. Por fim, consideramos os cursos configurados como práxis educativas devido situarem a interdisciplinaridade pautada nas Ciencias Sociais, no sentido de promover uma relação dialética entre as áreas do conhecimento, buscando uma formação docente crítica, emancipatória e transformadora.

Conexo as nossas inferências, pelo Gráfico 2 podemos observar que a maior parte das licenciaturas empregam o uso da interdisciplinaridade tomando como base os fundamentos do racionalismo técnico-pragmático, sobretudo os cursos de modo Presencial e EAD. As licenciaturas que se identificam com tal característica encontram-se, 35 de modo Presenciais, cinco em EAD e quatro Educação do Campo, as quais representam $61 \%$ dos cursos analisados.

Gráfico 2 - Quantitativo de PPPs que adotam a interdisciplinaridade com tendências ao modismo, técnico pragmático e como práxis emancipatória.

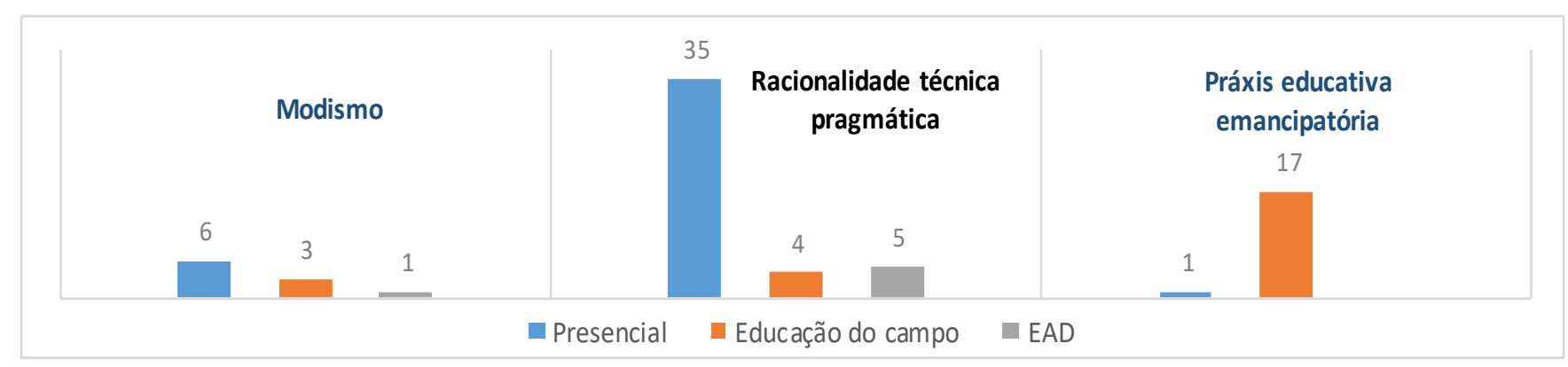

Fonte: Elaborado pelos autores a partir da análise de cada Projeto de Curso.

Assim, dos 72 cursos analisados, identificamos um total de dez licenciaturas (13,9\%) que anunciam a interdisciplinaridade de maneira infundada, privada de definições, sem estabelecimento de vínculos que pudessem transparecer elementos compreensíveis à proposta, o que impediu uma análise mais substancial de compreensão dada ao seu significado.

A esses cursos, em concordância com Feistel (2012) e Blauth (2015), classificamos seus propósitos com a interdisciplinaridade de aparência correlata a um modismo, pois são projetos que se apropriaram do discurso da interdisciplinaridade estando sujeitos a mais um movimento influenciado por tendências, tornando sua presença indiferente nos currículos de formação docente, incapaz de romper com o paradigma da disciplinaridade.

Segundo Coelho e Scremin, (2019), a ausência de esclarecimentos relacionados à interdisciplinaridade no currículo pode causar diferentes interpretações sobre este conceito no desenvolvimento das práticas pedagógicas dos professores que atuam nas licenciaturas.

Conforme Gráfico 3, esses cursos se encontram de modo Presencial, em sua maioria, com seis cursos, sendo dois na região Norte e dois no Sudeste. 
Gráfico 3 - PPPs dos cursos de LCN que não fundamentam a interdisciplinaridade.

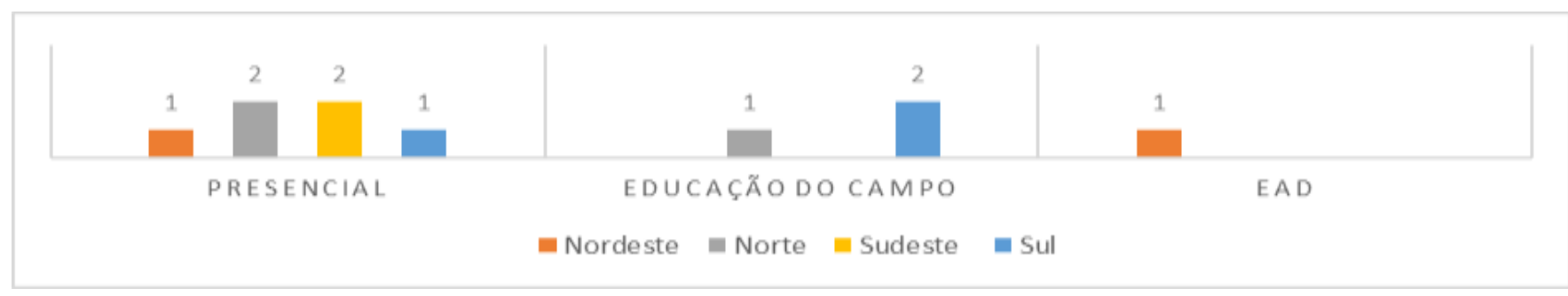

Fonte: Elaborado pelos autores a partir da análise de cada Projeto de Curso.

Quanto aos demais currículos, pertinentes aos outros 62 cursos, evidenciamos inicialmente uma singular concordância entre eles. Integralmente descrevem no escopo de seus projetos a aspiração em preparar professores com sólida formação a partir da indissolúvel relação entre teórica e prática.

Para tal, apontam a interdisciplinaridade como princípio educativo integrador e promotor dessa relação, devendo permear toda a formação docente. Destacam que o modelo proposto busca assegurar, ao longo do curso, a articulação da teoria às diferentes dimensões da prática docente, numa perspectiva integradora e íntima da tríade de conhecimentos de domínio: científicos (Biologia, Física e a Química)/didático-pedagógicos / humanos (político e social).

No que se refere às ações pedagógicas, com foco na realização da prática interdisciplinar para se atingir os objetivos do curso e o perfil desejado do egresso, nomeiam uma ou várias disciplinas encarregadas de promover a articulação entre os conhecimentos apreendidos e tratados durante o curso pelos diferentes componentes, distribuídos no fluxo da matriz curricular. São disciplinas consideradas integradoras, estando localizadas ou nos eixos ou em núcleos estruturantes de formação didáticopedagógica e, em alguns casos, como sendo uma atribuição exclusiva das disciplinas responsáveis pelas práticas de ensino e/ou pelos estágios supervisionados obrigatórios.

Pelo contexto apresentado entre os 62 PPPs, percebe-se a interdisciplinaridade posicionada teoricamente com conotação de práxis pedagógica, aliada a valorização da unidade teoria e prática para produção e reprodução do conhecimento científico conectado com a vida social, capaz de suscitar uma formação docente crítica e reflexiva. Tal compreensão, indica contribuir para a consolidação de um perfil profissional do egresso do curso em LCN comprometido com uma educação transformadora de caráter, até então, supostamente emancipatório.

Logo, ao analisarmos a amplitude e complexidade de como é proposta a condução prática do processo pedagógico de abordagem interdisciplinar dos componentes integradores, guiados pelos princípios orientadores de cada PPP, encontramos algumas dissonâncias. São discordâncias relacionadas aos conteúdos que deveriam lidar com a formação humana, de dimensão social do ser humano e sua relação histórica de dominação entre natureza e trabalho.

Desta maneira, conforme o Gráfico 4, em 44 licenciaturas (61\%) notamos a interdisciplinaridade compreendida e orientada pela perspectiva de formação fortemente situada na lógica do tecnicismo pragmático. 
Gráfico 4 - PPPs analisados que tratam a interdisciplinaridade com sentido técnico-pragmático, conforme modalidades e regiões.

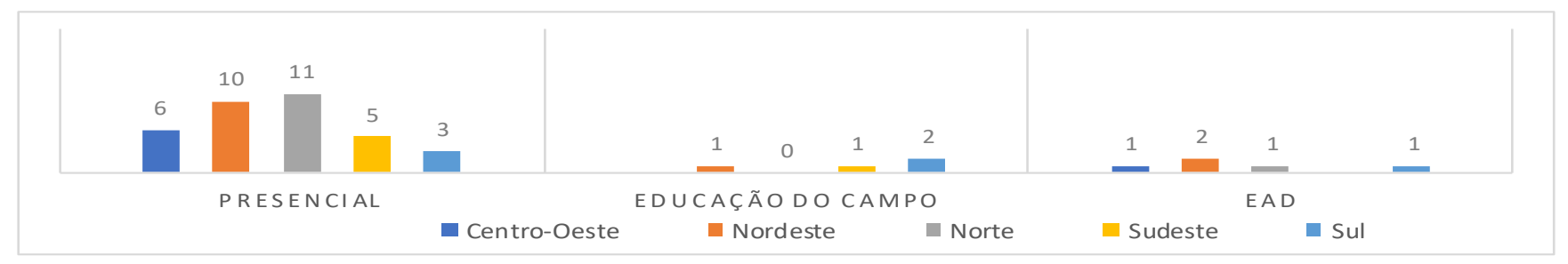

Fonte: Elaborado pelos autores a partir da análise de cada Projeto de Curso.

Por sua vez, 18 cursos (25\%), anunciam a interdisciplinaridade com tendência de práxis educativa emancipadora, identificados no Gráfico 5.

Gráfico 5 - PPPs analisados que tratam a interdisciplinaridade com sentido de práxis emancipadora, conforme modalidades e regiões

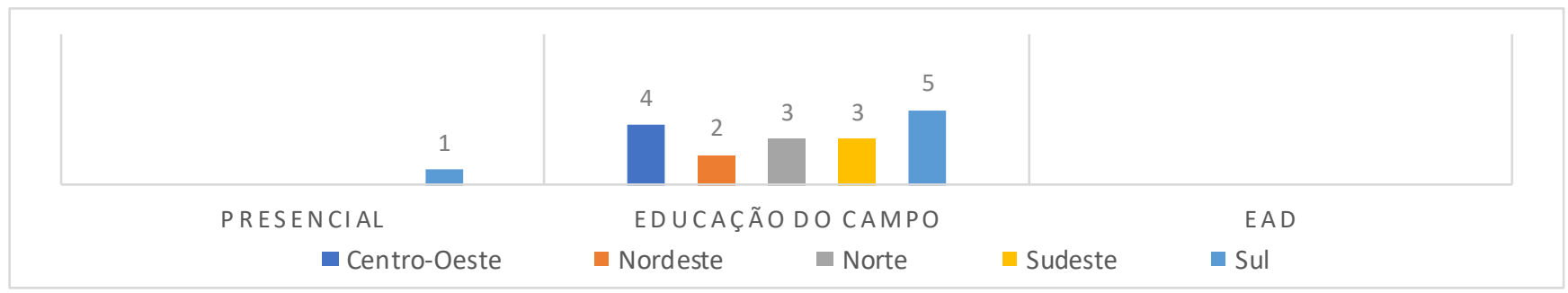

Fonte: Elaborado pelos autores, com base na análise de cada Projeto de Curso.

Com aspecto da racionalidade técnica e pragmática, destacam-se as LCNs Presenciais, com 35 cursos, sobressaindo as que se encontram nas regiões Norte e Nordeste, ao passo que 4 licenciaturas em Educação do Campo apresentam as mesmas particularidades. Importante sublinhar que de todos os seis cursos em EAD investigados, cinco (83\%) assumem a interdisciplinaridade com tais características. Deste modo, evidenciamos 44 cursos com viés tecnicista pragmático.

A abordagem dada à formação interdisciplinar por estas licenciaturas incide na junção de componentes específicos e pedagógicos ou na visão compartimentalizada das Ciências, com propósito único de interrelacioná-las para o desenvolvimento de procedimentos reduzidos a técnicas de aplicação dos conteúdos que cingem as áreas da Ciências da Natureza, tratadas no currículo escolar. Como nos anos 60 e 70, visam o preparo de educadores especialistas, em que a partir do entendimento dos diversos saberes científicos produzidos se voltam para execução de um ensino de Ciências nas escolas para se chegar à resolução de problemas com fins utilitários (Delizoicov, Angotti \& Pernambuco, 2007).

Para Etges (1993), o que os alunos aí aprendem é a cooperação entre as disciplinas meramente para resolver problemas práticos que surgem na escola, no trabalho e em suas vidas diárias. Assim sendo, não fazem ação interdisciplinar, nem aprendem propriamente a pensar criticamente nestes termos e a buscarem soluções para os problemas de contexto social gerados pela economia política capitalista.

A seguir são apresentados alguns trechos que abreviam nossas constatações, pois os textos são bastante similares entre os PPPs.

[...] portanto, a formação interdisciplinar do curso é resultado da sobreposição dos conhecimentos específicos de Biologia, Física, Química e da área de Educação (PPP 38-Sul-EP, 2017, p. 33). 
As disciplinas básicas deverão ser desenvolvidas de forma a proporcionar aos estudantes de Licenciatura em Ciências o conhecimento dos princípios físicos, químicos e biológicos envolvidos em cada subárea do conhecimento, deixando clara a interdisciplinaridade dos mesmos com essas áreas, apresentando a forma como estes conteúdos são repassados aos estudantes do Ensino Fundamental (PPP 28-Nordeste-EAD, 2018, p. 24).

$\mathrm{O}$ egresso do curso de Licenciatura em Ciências Naturais deverá ter ampla visão: estar apto em atuar multi e interdisciplinarmente, adaptável à dinâmica do mercado de trabalho e às situações de mudança contínua do mesmo (PPP 5-Norte-EP, 2019, p. 26).

O curso de Licenciatura em Educação do Campo obedece às Resoluções e Legislações específicas sobre formação de professores, [...] reconhecem que a predominância da visão fragmentada do conhecimento presente nos anos finais do Ensino Fundamental e no Ensino Médio poderá se romper pela interdisciplinaridade, para que as novas propostas de ensino se desdobrem em práticas didáticas na sala de aula (PPP 16-Sudeste-EC, 2018, p. 7-8).

Pelos fragmentos observa-se que não são cogitadas mediações dialéticas entre os saberes de dimensão teórica, relacionadas às áreas das ciências humanas. Como destaca Frigotto (2008, p. 51), "É neste sentido que a teoria se constitui em força material e a consciência crítica um elemento fundamental e imprescindível na luta pela transformação das relações sociais marcadas pela alienação e exclusão".

A interdisciplinaridade vista por esse ângulo, como método/técnica de ensino, se confunde com o conceito de multidisciplinaridade, devido as disciplinas não estabelecerem uma relação dialética da realidade social, pautada pelo princípio dos conflitos e das contradições (Frigotto, 2008), não promovendo, portanto, uma educação libertadora e emancipatória (Freire, 2009). Tonet (2013) complementa a ideia elucidando que para o enfoque interdisciplinar, com perspectiva de práxis emancipatória, os conteúdos não podem estar separados das questões relacionadas à estrutura capitalista, das lutas de classes dos explorados e dominados, dos meios de produção, do mundo cotidiano longe do trabalho e, sobretudo, despolitizados.

A ausência, por abordagem teórica, de aspecto humanístico e libertador, como meio de nutrir a prática, elemento fundante da práxis interdisciplinar transformadora, também está presente em alguns currículos dos cursos de LCN, conforme apontam os trabalhos de Mueller, Bianchetti e Jantsch, (2008), Feitosa (2019), Coelho e Scremin (2019) e Muenchen e Sául (2017).

Em referência aos PPPs das 18 licenciaturas, os quais depreendemos do contexto teórico de suas proposições se apropriarem da interdisciplinaridade ou da integralidade com intenções de promover uma educação emancipadora, se deve por expressá-la não como um método de soma de disciplinas voltado para resolução de problemas práticos. Ao contrário dessa visão pragmática, tais cursos situam a interdisciplinaridade primeiramente no plano ontológico do ser social, expressa nos fundamentos históricos de produção capitalista que deram origem a fragmentação do saber. E, secundariamente, ela é posicionada num plano de corrente epistemológica mais amplo de organização pedagógica curricular, que envolve a comunicação e interação entre as disciplinas a partir de uma práxis social interdisciplinar.

Com esse princípio, perspectiva-se a apropriação crítica e reflexiva pelos licenciandos dos saberes hegemônicos produzidos e negados, de maneira a permitirem uma visão totalizadora frente às realidades do modo de produção da vida material, social e do trabalho, estando comprometidos com uma educação transformadora dessa realidade concreta.

Os fragmentos descritos abaixo conferem a interdisciplinaridade compreendida por estas licenciaturas conforme delineadas acima.

Dessa forma, cabe situar o desenvolvimento da matriz curricular que se deu a partir da compreensão da produção do conhecimento, isto é, integrando diferentes campos de estudos (História, Sociologia, Antropologia, Filosofia, Biologia, Matemática, Química, Física, entre outros). As especificidades teórico metodológicas desses campos são os pilares para a compreensão dos processos sociais constituídos na sua historicidade e em suas relações de trabalho, ou seja, nas relações que implicam homem-campo e sociedade (PPP 56-Centro-Oeste-EC, 2011, p. 20).

Estes conhecimentos teóricos e práticos que possuem "corpus específicos", conforme cada área, mas que se interrelacionam dialeticamente, devem ser desenvolvidos sob a perspectiva da interdisciplinaridade e que está sendo assinalada aqui como a viga mestra deste trabalho de formação acadêmica (PPP 41-Sul-EP, 2011, p. 48). 
Acreditamos que o desenvolvimento de novas práticas pedagógicas e sociais, por intermédio de uma atitude interdisciplinar da docência, possibilita desencadear meios para superar a produção de conhecimentos fragmentados e as condições de injustiça e opressão a que estão submetidos, principalmente, os trabalhadores do campo (PPP 43-SulEC, 2019, p. 13).

Notadamente, a interdisciplinaridade se apresenta como processo educativo tratado no âmbito das ciências sociais, orientada a perpassar por todas as etapas da matriz disciplinar, estando responsável pela relação dialética entre os conhecimentos das diversas áreas das Ciências da Natureza e Sociais. Por esta ótica, ela se constitui como um movimento pedagógico, que visa sobrepujar a dicotomia teoria-prática de maneira a transforma a sala de aula (universidades e escolas) em espaço de reflexão e de cessamento das inúmeras formas de dominação, opressão ou de qualquer ato discriminatório que transcorre os ambientes de ensino e na sociedade.

Como já apontado no Gráfico 5, dos 18 cursos que dão enfoque à interdisciplinaridade com sentido de práxis, sobressaem as Licenciaturas em Educação do Campo, com 17 cursos dispostos em cada região, enquanto na modalidade presencial localizamos apenas um, na região Sul. Tal achado despertou atenção, o que nos levou a constatar que os PPPs desses cursos possuem uma estrutura organizacional bastante peculiar. A formação de educadores das LEdoC se dá a partir de um currículo organizado pelas quatro grandes áreas de conhecimento: Artes, Literatura e Linguagens; Ciências Humanas e Sociais; Ciências da Natureza e Matemática; e Ciências Agrárias.

Ao analisarmos a relação da interdisciplinaridade e a formação por área do conhecimento, proposto pela Educação do Campo, percebemos, como Molina (2017), que um dos principais objetivos do curso é a possibilidade de os formandos atuarem em vários contextos disciplinares, atendendo a demanda de professores da Educação Básica no território rural. Contudo, a autora esclarece que sua intencionalidade maior é a de contribuir com a construção de processos capazes de desencadear mudanças na lógica capitalista de utilização e de produção de conhecimento no Campo.

Para esse fim, os currículos das LEdoC estão estruturados de modo a permitir que os licenciandos transitem por todas as quatro áreas de conhecimento, dispostas em três núcleos de formação (Formação Básica, Formação Específica e Práticas Integradoras), orientados a articularem interdisciplinarmente. Assim, no decorrer do curso, o estudante aprofunda em uma das quatro áreas a qual deseja ser habilitado para atuar como docente, no caso dos cursos analisados na área de Ciências da Natureza.

De acordo com o PPP 22-Nordeste-EC, a formação por área do conhecimento busca construir um olhar interdisciplinar para os fenômenos das realidades e os processos sociopolíticos analisados, a partir do contexto vivido. Por isso, os núcleos formativos precisam ser ofertados gradualmente, permitindo a interdisciplinaridade, a integração dos saberes e a construção da práxis emancipatória na Educação do Campo.

Ao menos no campo teórico, explícito nos currículos das LEdoC, repara-se indicadores que validam intenções em preparar educadores pelo princípio da interdisciplinaridade, articulando os conhecimentos em suas diferentes dimensões (cientificas, políticas, filosóficas, sociais, humanas, entre outras). Para Frigotto (2008), isso significa transcender as fronteiras da fragmentação e o plano fenomênico das disciplinas, heranças fortes do empirismo e do positivismo.

Acentua-se que estas reflexões não se aplicam a todos currículos organizados por área de conhecimento. Como evidenciado, existem outras licenciaturas que dizem interdisciplinarizar o curso pela integração dos saberes das diferentes áreas e, no entanto, situam a interdisciplinaridade nos projetos como soma arbitrária das partes, com a crença de estarem proporcionando nos educadores em formação, uma visão mais ampla de mundo para se emanciparem. Não parece ser considerado que para haver apreensão da realidade em sua totalidade, a interdisciplinaridade deve ser vista como exercício educativo a partir da dialética entre os conteúdos, voltado para o contexto de cunho social, político histórico e cultural, em direção oposta ao racionalismo técnico, pragmático de lógica capitalista. 


\subsection{Categoria Educação de Jovens e Adultos como campo de atuação profissional na formação inicial de professores de} Ciências

Nesta categoria de análise foi considerada a modalidade de Educação de Jovens e Adultos, prevista formalmente em cada projeto de curso como campo de atuação dos licenciandos em Ciências, tendo em vista as determinações legais e a oferta de componentes curriculares relacionados à modalidade, explícitos na composição de suas matrizes.

Por meio das matrizes e ementas de cada currículo, do total de 72 cursos pesquisados, constatamos um conjunto constituído por 37 licenciaturas (51\%) que não citam a modalidade EJA em nenhum momento nos seus projetos, nem mesmo a pondera como possível campo de atuação profissional dos egressos.

Embora muitos desses PPPs tenham sido elaborados há mais de uma década, tal lacuna não se justifica, pois, a modalidade é prevista desde a LDBEN de 1996, reforçada pelas DCNs para Formação de Professores da Educação Básica, em nível superior (BRASIL, 2002, 2015 e 2019). Notadamente, as normas prescritas pelas legislações não foram incorporadas por metade das licenciaturas examinadas, especialmente nos cursos Presenciais e EAD (28 Presenciais, quatro em Educação do Campo e cinco em EAD).

Por outro lado, identificamos um outro grupo composto por nove cursos (dois Presenciais e sete do Campo), que declaram titular educadores licenciados capazes de desempenhar à docência em todas as modalidades de educação, especialmente no âmbito da EJA. Entretanto, de modo idêntico ao grupo anteriormente citado, não identificamos em suas matrizes a inclusão, ou indícios, de componentes curriculares direcionados à temática.

Ao que parece, reportam à EJA em seus princípios políticos e pedagógicos para acatar aos preceitos das legislações vigentes. Contudo, não ofertam disciplinas com propósito efetivamente formativo de educadores, comprometidos com a inclusão de jovens e adultos no processo de socialização do conhecimento em Ciências.

Se destacam com esta particularidade sete licenciaturas indicadas em Educação do Campo, assim localizadas: três na região Sul; duas no Centro-Oeste, uma no Norte e uma no Sudeste. Alegam que para atingir algumas das metas propostas para a Educação do Campo, dentre elas as demandas por educadores de Ciências aptos a atuarem com adultos camponeses do Ensino Fundamental, as atividades de estágio e de práticas pedagógicas estão organizadas e orientadas a inserirem os licenciandos nas escolas que atendam, prioritariamente, a EJA. Ainda assim, não localizamos componentes curriculares em suas matrizes com tal finalidade, ficando, portanto, à margem do discurso.

Assim, diante da análise dos currículos e das matrizes dos dois grupos nos foi permitido inferir que 46 cursos (63\%) não demonstram preocupações efetivas com o preparo inicial do educador de Ciências para exercer a docência junto ao público jovem e adulto da Educação Básica. Por conseguinte, depreendemos que um total de 26 cursos (36\%) apresentam grades curriculares compostas por uma ou mais disciplinas correlatas à modalidade, sendo doze Presenciais, treze LEdoC e um EAD.

Das 46 licenciaturas aqui apontadas por não contemplarem a modalidade EJA, consideramos a possibilidade de alguns dos seus PPPs terem sidos idealizados em circunstâncias distintas, visto que existem outros cursos de LCN ofertados pela mesma IES, em diferentes campi, que preveem a EJA na matriz curricular. É o caso de quatro universidades nos estados do Pará, Bahia, Santa Catariana e Rio Grande do Sul, as quais dão atenção à EJA em certos PPPs enquanto em outros não.

Concisamente, na ênfase dada por estes PPPs prepondera a formação docente para o desempenho de suas funções no ensino regular, destinado a crianças e adolescentes inseridos nos anos finais do Ensino Fundamental. Como consequência, nada é apreendido e tratado com finalidade educativa sobre a realidade diferenciada, de sentidos próprios vivenciados pelos sujeitos jovens, adultos e idosos (Cassab, 2016).

Como afirmam, Bomfim (2015, 2017), Arroyo (2017) e Di Pierro e Haddad (2015), a EJA ainda ocupa posição marginal nas políticas curriculares, sobretudo nos projetos políticos de formação das universidades, que rejeitam o olhar sobre a necessidade de formar educadores preparados para a juventude que frequenta a modalidade. Sem a devida qualificação, os 
professores passam a desenvolver metodologias (técnicas, recursos e atividades) sem qualquer significado ou valor social para os alunos-trabalhadores (Moura, 2009).

\subsection{Categoria conhecimentos priorizados nas ementas dos componentes curriculares com abordagem na EJA}

Esta categoria emergiu a partir do cruzamento dos dados obtidos e refletidos nas duas primeiras categorias discutidas. Ou seja, a análise se deu por meio dos ementários dos 26 cursos localizados que, de alguma forma, contemplam a EJA em suas matrizes, tendo como parâmetro a categoria interdisciplinaridade interpretada como proposta em cada PPP. Sua finalidade consistiu em compreender a organização interdisciplinar de integração entre os saberes, assim como a relação teoria e prática para produção dos conhecimentos pretendidos sobre a modalidade EJA no processo formativo inicial dos licenciandos.

Diante das considerações, localizamos ao todo 45 disciplinas, sendo 36 reconhecidas como obrigatórias e nove optativas, que se apresentam por nomenclaturas variadas, denominadas pela maioria de Educação de Jovens e Adultos; Estágio Supervisionado na EJA; Ação docente na EJA e Educação Popular.

Ao examinarmos os elementos explícitos e implícitos presentes em cada ementa, observamos características particulares no conjunto de disciplinas selecionadas, havendo a necessidade de delimitá-las em subcategorias por disciplinas para haver melhor coerência nas análises. As subcategorias definidas como referência para análise de conteúdos vinculados aos conhecimentos da EJA e suas minudências são:

I. Fundamentos teóricos - disciplinas estritamente teóricas, sem carga horária para atividades práticas. Todas são de quatro créditos (carga horária de 60 horas);

II. Estágio supervisionado - se encarregam de acompanhar o graduando no desenvolvimento das práticas pedagógicas interventivas nas escolas da EJA, aliando teoria e prática. Acontecem a partir do quinto semestre. Variam entre 6 e 7 créditos (90 a 105 horas);

III. Práticas de ensino - disciplinas consideradas integradoras ou interdisciplinares, desenvolvidas também com caráter teórico e prático no ambiente escolar. Encontradas apenas nos cursos da LEdoC. Difere dos estágios por contextualizar a realidade escolar da EJA desse o início do curso por meio de seminários temáticos de integração. Entre 4 e 6 créditos (60 e 90 horas);

IV. Optativas - disciplinas não obrigatórias, eventualmente ofertadas no curso, todas de 4 créditos (60 horas).

Conforme a Tabela 2, os componentes quando somados se encontram em maior número nos treze cursos da LEdoC, apresentando 25 disciplinas (55,5\%) que totalizam carga horária de 1.650h (1.530 obrigatórias e 120 optativas). Em seguida temos os doze cursos de modo Presencial, dispondo de 19 disciplinas (42,2\%) que juntas somam 1.470 horas (1.050 obrigatórias e 420 optativas).

Nestes dois modos de licenciaturas as disciplinas são ofertadas por 22 IES (doze LEdoC e dez Presenciais), em diferentes campi, dispersas quantitativamente em doze estados brasileiros. Quanto aos cursos em EAD, localizamos uma única disciplina em todos os seis cursos alcançados pela pesquisa, sendo de caráter puramente teórico, sem horas de práticas, ofertada por uma única IES situada no estado do Piauí. 
Tabela 2 - Número de disciplinas voltadas para EJA segundo subcategorias de análise, modalidade, Estados Federativos e Carga Horária (C.H).

\begin{tabular}{|c|c|c|c|c|c|c|c|c|c|}
\hline \multirow{2}{*}{$\begin{array}{l}\text { Subcategorias por } \\
\text { disciplinas }\end{array}$} & \multicolumn{9}{|c|}{ Modalidades } \\
\hline & $\mathbf{N}^{0}$ & $\begin{array}{r}\text { Presencial } \\
\text { Estados }\end{array}$ & C.H & $\mathbf{N}^{\circ}$ & $\begin{array}{l}\text { LEdoC } \\
\text { Estados }\end{array}$ & C.H & $\mathbf{N}^{\mathbf{o}}$ & $\begin{array}{r}\text { EAI } \\
\text { Estado }\end{array}$ & C.H \\
\hline $\begin{array}{l}\text { Fundamentos } \\
\text { Teóricos }\end{array}$ & 1 & 1-Rio Grande do Sul & 60 & 12 & $\begin{array}{l}\text { 1-Espirito Santo; 1-Pará; } \\
\text { 1-Minas Gerais;2-Bahia; } \\
\text { 4-Rio Grande do Sul; } \\
\text { 1-Paraná; 2-Goiás }\end{array}$ & 720 & 1 & Piauí & 60 \\
\hline $\begin{array}{c}\text { Estágio } \\
\text { Supervisionado }\end{array}$ & 11 & $\begin{array}{c}\text { 6-Piauí; } \\
\text { 1-Distrito Federal; } \\
\text { 1-São Paulo; 1-Rio } \\
\text { de Janeiro; 1-Rio } \\
\text { Grande do Sul; } \\
\text { 1-Paraná } \\
\end{array}$ & 990 & 5 & $\begin{array}{l}\text { 1-Pará; 2-Goias; } \\
\text { 1-Distrito Federal; } \\
\text { 1-Minas Gerais }\end{array}$ & 450 & 0 & ----- & ----- \\
\hline $\begin{array}{l}\text { Práticas como } \\
\text { componente } \\
\text { curricular-PCC }\end{array}$ & 0 & ------------------------ & 0 & 6 & $\begin{array}{l}\text { 1-Pará; 2-Bahia; } \\
\text { 3-Rio grande do Sul }\end{array}$ & 360 & 0 & ----- & ----- \\
\hline Optativa & 7 & $\begin{array}{c}\text { 1-Rio de Janeiro; } \\
\text { 6-Mato Grosso }\end{array}$ & 420 & 2 & $\begin{array}{c}\text { 1-Distrito Federal; } \\
\text { 1-Goiás } \\
\end{array}$ & 120 & 0 & ----- & ----- \\
\hline Total & 19 & 10 IES & 1.470 & 25 & 12 IES & 1650 & 1 & 1 IES & 60 \\
\hline
\end{tabular}

Fonte: Elaborado pelos autores a partir das ementas de cada Projeto de Curso.

No que diz respeito à integralização da carga horária total de todos os componentes, prevista no desenho curricular, verificou-se que os 26 cursos contemplam a carga horária mínima estipulada pelas diretrizes em vigor no período em que cada PPP fora produzido. Antes da Resolução n. 02 de 2015 eram de 2.800 horas e, atualmente, após esta resolução passou a ser 3.200 horas. Observamos que alguns PPPs excedem a carga menor exigida.

$\mathrm{Na}$ análise das matrizes referentes ao grupo classificado como voltado à interdisciplinaridade com teor pragmático, confirmou-se a predominância fragmentária de componentes direcionados à EJA. A Educação de Jovens e Adultos é tratada por disciplinas reservadas e isoladas das demais. Ela não aparece em nenhum componente correlato às áreas de formação social, política, filosófica, psicológica e didático-pedagógicas, nem mesmo é mencionada nos conteúdos programáticos relacionados aos fundamentos da Educação.

O mesmo quadro também foi reparado, inclusive, em cinco PPPs constituintes do grupo que em nossa análise advogam a interdisciplinaridade com perspectiva de práxis educativa transformadora (um Presencial e quatro Educação do Campo).

Ao mesmo tempo, ao examinarmos os conteúdos anunciados pelas ementas desses cursos, notamos o tratamento dado à EJA ainda recuada das dimensões sociais, culturais e políticas. Pelos dados depreende-se 17 cursos (doze Presenciais, quatro LEdoC e um EAD) nos quais, embora contemplem a modalidade, não foi possível localizar em suas ementas indicadores que pudessem evidenciar algum tipo de direcionamento no sentido de se constituir uma práxis interdisciplinar potencialmente politizada, engajada como processo formativo de educadores para compreensão da EJA em sua totalidade, com efeito de transformação e de intervenção social.

Ainda que alguns desses currículos considerem a EJA em mais de uma disciplina, é notório em todas as subcategorias, sobremaneira nos componentes obrigatórios, a inexistência de manifestações por temáticas com interesse em promover discussões e estudos acerca da classe trabalhadora e suas relações históricas de dominação entre ser humano, natureza e trabalho. 
Como defende Arroyo (2017), o passo decisivo para reinvenção da EJA é ter nos currículos de formação de educadores o trabalho como referência ético-político-pedagógica, devendo ser incorporadas às condições sociais e políticas dos trabalhadores e a história da diversidade de movimentos de libertação do movimento operário de que são herdeiros. Ver os educandos jovens e adultos sem os perceberem como trabalhadores/as oprimidos, alienados e injustiçados, exigem outras pedagogias, outros projetos de formação de educadores.

Ademais, algumas ementas acentuam, como conteúdo programático, a necessidade de explanar os problemas enfrentados pela EJA. Ainda assim, não se verifica indicações de quais temáticas ou assuntos que poderão ser trabalhados em cada tópico para se discutir as problemáticas sugeridas. Os textos são superficiais, resumidos e com pouco conteúdo, sem esclarecimentos daquilo que se espera com a disciplina e dos procedimentos a serem realizados. São disciplinas compartimentalizadas, compatíveis às desenvolvidas nas escolas noturnas da Educação Básica (Barcelos, 2012; Moretto, 2016; Cassab, 2016).

Machado (2008) e Gadotti e Romão (2011) ressaltam que com a falta de organização curricular, corre-se o risco dos professores formadores das licenciaturas deixarem de enfatizar nos cursos a importância dos educadores em formação inicial reconhecerem a trajetória, a diversidade, os direitos, as políticas públicas existentes, o contexto socioeconômico e cultural e a valorização das experiências trazidas para a sala de aula próprias do jovem e do adulto. Por conseguinte, os licenciandos em Ciências são impossibilitados de compreenderem as reais necessidades desse público com o ensino em suas futuras ações docentes, deixando de os auxiliarem na transformação de suas realidades.

Por estas licenciaturas, nas subcategorias Fundamentos Teóricos e Optativas, não preverem carga horária de atividades de práticas, observamos que, em regra, a preocupação se concentra em fornecer aos graduandos aportes teóricometodológicos e didáticos, com a ideia principal de ensiná-los a ensinar Ciências aos jovens e adultos.

Consideramos ser também importante para o educador de Ciências em formação, o desenvolvimento de repertórios ampliados dos conhecimentos científicos, com abordagens apropriadas e contextualizadas para todas as etapas e modalidades da Educação. Portanto, assentimos com Ventura (2012), Jesus e Nardi (2016) que as ementas curriculares das licenciaturas reduzidas tão somente com essa visão, especialmente àquelas voltadas para a EJA, não permitem assegurar uma formação promotora de transformação social e de construção de um projeto societário contra hegemônico.

Como todo componente curricular de caráter teórico-prático sugere em suas ementas o desenvolvimento das teorias a ele relacionado, na análise das subcategorias Estágio Supervisionado e Práticas como Componente Curricular (PCC) avaliamos, nos PPPs em pauta, características teóricas similares às demais. Em ambas as disciplinas o que se verifica nos textos, por menores que sejam, é a teorização das práticas de regência e de intervenção dos graduandos voltadas para o desenvolvimento de metodologias para o ensino de Ciências, limitadas ao contexto da sala de aula da EJA. As ações educativas são conduzidas sistematicamente pelos conhecimentos apreendidos no curso, associadas à transmissão dos conteúdos determinados nos currículos escolares, cuja principal finalidade é o "como" e "o quê" ministrar nas aulas.

Fica evidente nas ementas que a formação prática dos futuros educadores é adquirida na e pela experiência, usualmente entendido como "aprender fazendo" (Luz, 2018), centrado na epistemologia da prática de políticas neoliberais para a aquisição de habilidades que usará no exercício de suas práticas futuras.

No sentido descrito, a formação docente se dá a partir das reflexões sobre as práticas pedagógicas ocorrida no âmbito da EJA, por meio de teorias consideradas insuficientes para estimularem o movimento da práxis. São teorias restringidas dos fatores externos à escola, que não conseguem explicar os problemas sociais e econômicos que afetam os educandos, os quais os educadores irão se deparar nas escolas, com poucas chances de oferecer meios para tentar modificá-los (Curado, 2019).

Em contrapartida, o estudo constatou nove cursos, 34,6\% do total de 26, que explicitam nas ementas tratamentos e procedimentos de ensino dos conteúdos formativos para a EJA diferentes do cenário das licenciaturas relatadas. Até certo 
ponto, estas valorizam, como parte da docência, o domínio de saberes concernentes ao campo pedagógico, tanto quanto dos saberes das áreas especificas das Ciências. Todavia, para além desse pensamento exíguo, exprimem intencionar a apreensão de um trabalho interdisciplinar na EJA guiado pela práxis, para que os discentes dos cursos sejam também aportados de recursos que os auxiliem num trabalho pedagógico de natureza emancipatória.

Os nove cursos que se destacam com essa concepção referem-se às Licenciaturas em Educação do Campo, apontadas na categoria interdisciplinaridade com currículos tendentes à práxis interdisciplinar de viés crítico, estando localizadas: uma no Pará; uma em Minas Gerais; duas na Bahia; duas no Rio Grande do Sul; uma em Goiás; uma em Santa Catarina e uma no Distrito Federal.

As matrizes dos PPPs de cada uma dessas licenciaturas apresentam entre duas e três disciplinas obrigatórias direcionadas à EJA, com carga horária mínima de 90 e máxima de 135 horas, responsáveis pela fundamentação teórica e as atividades de intervenção prática, que ocorrem in loco nas Escolas do Campo que atendem a modalidade. Esta última é realizada por intermédio ou das disciplinas de PCC ou de Estágio Supervisionado, ou então das duas em semestres intercalados, conforme presenciado em um PPP do curso situado no estado do Pará.

Em suas ementas, por meio de tópicos, exibem um elenco de conteúdos programáticos conceitual/procedimental a serem trabalhados, priorizando as dimensões humanas, antropológicas, econômicas, políticas e culturais, consoantes com a realidade para desvelarem as condições opressoras do mundo do trabalho vivenciada pelos camponeses jovens e adultos.

Os trechos abaixo, extraídos das ementas, dão mostras de que os cursos compreendem a necessidade de um trabalho interdisciplinar na formação de educadores em Ciências junto à EJA, tendo por base a práxis educativa, crítica e dialógica, em que a realização das atividades de prática docente possam considerar, à luz da teoria:

A EJA e a Educação popular, trabalho e renda; Desafios e perspectivas da EJA frente às transformações da Educação e no Mundo do Trabalho; Movimentos sociais e suas contribuições para a EJA; A contribuição dos movimentos sociais na elaboração e implementação de políticas públicas; Cultura política, educação e sociedade; A Educação emancipadora (PPP 53-Centro-Oeste-EC);

Os pressupostos históricos e teóricos da Educação de Jovens e Adultos no Brasil. O papel do educador na EJA e os saberes indispensáveis à sua prática. Projetos interdisciplinares para o ensino-aprendizagem na EJA. A heterogeneidade do contexto atual da EJA no Brasil. A EJA nas comunidades rurais do Cerrado (PPP 18- SudesteEC);

Estudo da EJA nas suas dimensões sociais, econômicas e políticas, vinculando suas concepções e práticas educativas ao contexto da América Latina, em geral, e brasileiro, em particular (PPP 24-Nordeste-EC).

Pela extensa carga horária e a lista de conteúdos indicado pelas disciplinas, coerentes com as demandas sociais dos sistemas de ensino da EJA, vê-se os PPPs dessas licenciaturas demonstrarem evidências de um projeto emancipador, compromissado com a formação de educadores capazes de perceberem as realidades e atuarem como agentes transformadores da EJA, tal como proposto por Arroyo (2006, 2017), Ventura (2012) e Cassab (2016).

Conforme Giroux (1997), trata-se da busca por formação de docentes como intelectuais transformadores, ajudando-os a adquirirem um conhecimento crítico sobre as estruturas sociais básicas, como o Estado, o mundo do trabalho e a cultura de massas, dirigidas à progressiva educação humanizadora e da ordem social nas escolas e nas comunidades.

Por conta das especificidades da LEdoC, outra característica encontrada relaciona-se à maneira como seus currículos são estruturados, pelo método de alternância. Em síntese, a formação docente é desenvolvida em espaços alternados de dois tempos: Tempo Universidade (TU), que ocorre na academia e o Tempo Comunidade (TC), compreendido como o tempo de exercício das práticas pedagógicas nas escolas do Campo. 
Em razão disso, verificou-se nos nove cursos, mediante a subcategoria Práticas como Componente Curricular (PCC), que parte das 400 horas deste componente é concedida a mobilizar os trabalhos realizados na EJA, alcançados no período de TU e TC, diferentemente das outras licenciaturas que não citam a modalidade nas PCC.

As PCC se encontram organizadas na forma de projetos, oficinas ou seminários temáticos, tidos como espaços integradores/interdisciplinares. São momentos destinados às problematizações, discussões, socializações e reflexões das atividades educativas experimentadas nas salas de aula, designadas à EJA durante a realização do Estágio ou das próprias PCC. Conforme identificado nos PPPs, esses momentos são efetivados ou no TU ou no TC, devendo ser obrigatoriamente coordenados e acompanhados por docentes do curso.

Como destaca o PPP 22-Nordeste-EC, o que se busca com a PCC é reforçar no licenciando o desenvolvimento da ação interdisciplinar a partir da articulação dos conhecimentos científicos e dos processos sociopolíticos estudados e analisados no TU, voltados para a transformação da realidade concreta dos educandos, experimentada na comunidade EJA local, observados no TC.

Segundo Sartori, Silva e Pagliarin (2019), a ideia que permeia tal concepção e organização curricular, é que tanto a universidade quanto a população do Campo são responsáveis pela formação desse docente, isto é, pela constituição do professor da escola do campo mediados pela pedagogia da alternância.

No caso específico desse grupo de licenciaturas, a leitura das ementas disciplinares nos permitiu inferir que a forma como estão selecionados e organizados os temas propostos para a EJA, tal como sua realização, intensifica na formação inicial docente a importância de um exercício constante da práxis interdisciplinar. A relação permanente do diálogo testemunhado entre os saberes de diferentes áreas, corroboram as ideias freireanas de práxis pedagógica libertadora, porque oportuniza o movimento dialético entre a teoria e a ação, requisito fundamental à formação interdisciplinar para uma visão humana e social da realidade.

\section{Considerações Finais}

Em suma, com base nas análises e nas reflexões realizadas pelo presente estudo, foi possível evidenciar que dos currículos referentes aos 72 cursos em Licenciaturas em Ciências Naturais, levantados por meio da base de dados do Sistema e-MEC, dezoito cursos (25\%) manifestam a interdisciplinaridade como proposta formativa posicionada com acepção de práxis pedagógica; somente 26 (36\%) apresentam grades curriculares compostas por disciplinas que tratam da EJA e, destes, apenas nove (12,5\% do total) propõem, nas ementas, ações interdisciplinares para o ensino de Ciências comprometido com as múltiplas necessidades sociais, políticas e culturais da população jovem e adulta inserida no contexto educacional, proporcionadoras de transformação da realidade concreta.

Desse modo, foram poucos os projetos que trazem disciplinas voltadas à EJA, e ficou evidente a predominância da temática discutida de forma fragmentada e superficial, sem relações com as outras áreas de conhecimento humano e social. Em razão disso, surgem contradições teórico/práticas entre um currículo e outro, e a predominância de uma educação interdisciplinar mais pragmática do que dialética, demonstrando que as instituições estão formando perfis acadêmicos diferenciados para a mesma profissão para atuarem com a EJA. Tal conjuntura revela a emergência por mudanças nesses currículos, para que a nova geração de professores de Ciências se aproprie de um conhecimento teórico-prático para além da apropriação e aplicação pedagógica de saberes científicos.

Exige-se, assim, currículos orientados a incentivarem os acadêmicos a incorporarem o desenvolvimento de um trabalho interdisciplinar, de concepção dialética, pautado na práxis como elemento norteador desse encadeamento. Isso requer ações pedagógicas socialmente significativas, capaz de despertarem no futuro educador a consciência crítico-criativa do seu papel social na educação da classe trabalhadora para a construção de uma sociedade mais justa e igualitária. 
Devido à natureza e o objetivo do estudo proposto, alcançamos um panorama geral das tendências das Licenciaturas em Ciências Naturais limitado aos Projetos Políticos e Pedagógicos de curso e ao âmbito das ementas previstas para a EJA. Em virtude das delimitações, é válido frisar que os dados apresentados são insuficientes para podermos concluir que este ou aquele curso se apresenta como um todo com características de formação pragmática, emancipatória ou neutra.

Para tanto, sugerimos ser necessário que outras pesquisas possam dar continuidade ao trabalho, analisando o currículo de uma instituição em particular. Assim, caberiam espaços para a realização de entrevistas e observações junto aos formandos e à equipe de formadores, visto que muitos destes podem abordar a EJA em seus planejamentos de ensino de maneira interdisciplinar, com perspectivas de ensino emancipador, mesmo não estando prevista em algumas das matrizes dos currículos.

De todo modo, acreditamos que esta pesquisa pode contribuir para o aprofundamento de discussões relacionados ao tema, além de colaborar com as reformulações curriculares dos cursos de licenciaturas, tornando a EJA, assim como as outras modalidades de ensino, lugar de destaque em seus currículos com propósito de educação transformadora.

\section{Referências}

Arroyo, G. M. (2006). Formar educadores de jovens e adultos. In: Soares, L. (Org.). Formação de educadores de jovens e adultos. (p. 17-32). Autêntica.

Arroyo, M. G. (2017). Passageiros da noite: do trabalho para a EJA. Itinerários pelo direito a uma vida justa. Vozes.

Barcelos, V. (2010). Educação de Jovens e Adultos: currículos e práticas pedagógicas. Vozes.

Bardin, L. (2010). Análise de conteúdo. Edições.

Blauth, W. (2015) Reflexões sobre a interdisciplinaridade. In Seminários de educação conhecimentos e processos Educativos, 1(2). http://periodicos.unesc.net/seminarioECPE/article/view/2219/2108\&gt.

Brasil (2002). Resolução CNE n 1, de 18 de fevereiro de 2002. Institui as Diretrizes Curriculares Nacionais para a Formação de Professores da Educação Básica em nível superior, curso de licenciatura, de graduação plena. Diário Oficial [da] República Federativa do Brasil, Poder Executivo.

Brasil (2015). Resolução CNE nº 2, de 9 de junho de 2015. Institui a Diretrizes Curriculares Nacionais para a Formação Inicial e Continuada dos Profissionais do Magistério da Educação Básica. Diário Oficial [da] República Federativa do Brasil, Poder Executivo.

Brasil. (2019). RESOLUÇÃO CNE/CP No 2, de 20 de dezembro de 2019. Define as Diretrizes Curriculares Nacionais para a Formação Inicial de Professores para a Educação Básica e institui a Base Nacional Comum para a Formação Inicial de Professores da Educação Básica (BNC-Formação). Diário Oficial da União Brasília, Seção 1, p. 46-49.

Cassab, M. (2016). Educação de Jovens e Adultos, educação em ciências e currículo: diálogos potentes. Educação em Foco, 21(12), 13-38.

Coelho, F. B. O., \& Scremin, G. (2019). A Interdisciplinaridade nas Licenciaturas em Ciências da Natureza: Análise de Projetos Pedagógicos de Cursos. XII Encontro Nacional de Pesquisa em Educação em Ciências - XII ENPEC: Universidade Federal do Rio Grande do Norte. http://abrapecnet.org.br/enpec/xiienpec/anais/busca_1.htm?query=a+rela\%7E\%E7\%E3o+

Craveiro, C. B., \& Freitas, A. V. (2019). Sentidos para a formação docente nas políticas curriculares em documentos Ibero-americanos e brasileiros: aproximações e distanciamentos. Journal of Supranational Policies of Education 6 (1), p. 110-123.

Cruz, A. C. (2018). EJA: A Formação Docente e seus Desafios na Preparação do Aluno para o Mundo Moderno. Revista Científica Multidisciplinar Núcleo do Conhecimento, 3(3), 5-17.

Curado, S. (2019). Epistemologia da práxis na formação de professores: perspectiva crítico-emancipadora. Mercado de Letras.

Delizoicov, D., Angotti, J. A., \& Pernambuco, M. M. Ensino de Ciências: Fundamentos e Métodos. Cortez.

Di Pierro, M. C., \& Haddad, S. (2015). Transformações nas políticas de Educação de Jovens e Adultos no Brasil no início do terceiro milênio: uma análise das agendas nacional e internacional. Cadernos CEDES, 35(8), 197-217.

Etges, N. J. (1993). Produção do conhecimento e interdisciplinaridade. Educação e Realidade, 2(18), 73-82.

Feistel, R. A. B. (2012). Contribuições da perspectiva freireana de educação para a interdisciplinaridade na formação inicial de professores de ciências. (Doutorado em Educação). Universidade Federal de Santa Catarina. https://repositorio.ufsc.br/xmlui/handle/123456789/130870+\&cd=1\&hl=pt$\mathrm{BR} \& \mathrm{ct}=\mathrm{clnk} \& \mathrm{gl}=\mathrm{br}$.

Feitosa, R. A. (2019). Uma crítica marxista à interdisciplinaridade. Acta Scientiarum. Education, 41(1), e 37750. https://doi.org/10.4025/actascieduc.v41i1.37750.

Freire. P. (2009). Pedagogia do oprimido. Paz e Terra. 
Frigotto, G. (2008). A Interdisciplinaridade Como Necessidade e Como Problema Nas Ciências Sociais. In. Ideação, 10(1), 41-62.

Frigotto, G. (2008). A interdisciplinaridade como necessidade e como problema nas ciências sociais. Ideação, 10(1), 41-62.

Gadotti, M., \& Romão, J. O. (2011). MOVA-SP Estados e Movimentos Populares. In: ROMÃO, José Eustáquio. (Orgs). Educação de Jovens e Adultos: teoria, prática e proposta. Cortez: Instituto Paulo Freire.

Giroux, H. A. (1997). Os professores como intelectuais: rumo a uma pedagogia crítica da aprendizagem. Artes Médicas.

Goodson, I. F. (1995). Etimologias, epistemologias e o emergir do currículo: teoria e história. Vozes.

Guba, E. G., \& Lincoln, Y. S. (1981). Avaliação eficaz: melhorando a utilidade dos resultados da avaliação por meio de abordagens responsivas e naturalísticas. Jossey-Bass.

Jesus, A. C., \& Nardi, R. (2016). Imaginários de Licenciandos em Física sobre a Educação de Jovens e Adultos e o Ensino nessa modalidade. Ensaio, 18(3), 51-71.

Lüdke, M., \& André, M. E. (1986). A pesquisa em educação: abordagens qualitativas. EPU.

Luz, A. S. (2018). As licenciaturas interdisciplinares no cenário nacional: implantação e processo. Tese (Doutorado em Educação) - Universidade Federal, Pelotas.

Machado, M. M. (2008). Formação de professores para EJA: uma perspectiva de mudança. Retratos da Escola, 2(5), $161-173$.

Moretto, M. (2016). Diálogos sobre a Educação de Jovens e Adultos: da exclusão à transformação social. EDUSF, 34(16), 105-108.

Moura, T. M. (2009). Formação de Educadores de Jovens e Adultos: Realidade, Desafios e Perspectivas Atuais. Práxis Educacional, 5(2), 45-72.

Muenchen, C., \& Sául, T. S. (2020). A interdisciplinaridade nas Licenciaturas em Educação do Campo nas Ciências da Natureza: possibilidades e desafios. Ensino Em Re-Vista, 27(1), 203-227.

Muller, R. R., Bianchetti, L., \& Jantsch, A. P. (2008). Interdisciplinaridade, pesquisa e formação de trabalhadores: as interações entre o mundo do trabalho e o da educação. Educação, Sociedade \& Culturas, 27(12), 175-192.

Ramos, L. O. L., \& Ferreira, R. A. (2018). Concepções de interdisciplinaridade na educação superior: uma análise dos projetos pedagógicos dos cursos de bacharelado interdisciplinar da UFBA. UNEB, 1(2), 105-131. https://www.revistas.uneb.br/index.php/cenaseducacionais/article/view/5681.

Rêses, E. S., Castro, M. R., \& Barbosa, S. (2018). Contribuição do materialismo histórico e dialético para o estudo da EJA. In: Rodrigues, M. E., \& Machado, M. M. (org.). Educação de jovens e adultos trabalhadores: produção de conhecimentos em rede. Appris, p. 79-102.

Sant' Anna, S. L., Mello, A. H., \& Stramare, O. A. (2017). Reflexões sobre a formação inicial de docentes em educação de jovens e adultos. Crítica Educativa, $3(2), 230-244$.

Sartori, J., Silva, D., \& Pagliarin, L. L. P. (2019). A pedagogia da alternância como possibilidade formativa nas licenciaturas em educação do campo. Ciência e Cultura, 24(6), 41-52.

Soares, L., \& Pedroso, A. P. F. (2016). Formação de Educadores na Educação de Jovens e Adultos (EJA): alinhavando contextos e tecendo possibilidades. Educação em Revista, 32(4), 251-268.

Thiesen, J. S. (2014). Currículo interdisciplinar: contradições, limites e possibilidades. Perspectiva, 31(2), 591-614.

Tonet, I. (2013). Interdisciplinaridade, formação humana e emancipação humana. Serviço Social, 2(116), $725-742$.

Ventura, J., \& Bomfim, M. I. (2015). Formação de Professores e Educação de Jovens e Adultos: O Formal e o Real nas Licenciaturas. Educação em Revista, 31(51), 211-227.

Ventura, J. (2012). EJA e os desafios da formação docente nas licenciaturas. Revista FAEEBA, 21(9), 71-82. 